\title{
Governança colaborativa para pesquisa em saúde: implicações da análise do Programa Pesquisa para o Sistema Único de Saúde
}

\section{Rafael Marques Pessoa \\ Reynaldo Maia Muniz Ivan Beck Ckagnazaroff}

Universidade Federal de Minas Gerais (UFMG), Belo Horizonte - MG, Brasil

A presente pesquisa busca analisar a governança colaborativa no âmbito da implementação do Programa Pesquisa para o Sistema Único de Saúde: Gestão Compartilhada em Saúde (PPSUS), em três estados brasileiros selecionados (Minas Gerais, Paraná e Sergipe), entre os anos de 2002 e 2016, utilizando-se o modelo teórico de Ansell e Gash (2008). Para cumprir esse objetivo, o estudo utiliza método qualitativo, procedimentos de estudo de caso, bem como coleta de dados mediante análise documental e entrevistas de campo nos três estados selecionados. Conclui que o processo de governança colaborativa no âmbito do PPSUS, nos três estados analisados, ocorre de maneira incompleta e que, apesar do desenho colaborativo do programa e da existência de decisões conjuntas, a implementação das ações encontra-se limitada pelos recursos, conhecimentos e processos disponíveis em cada organização participante do arranjo do programa. Isso significa que tais elementos influenciam fortemente o processo colaborativo, constatação a partir da qual se propõe incluir no modelo teórico uma categoria denominada "capacidade de gestão intraorganizacional".

Palavras-chave: governança colaborativa, tecnologia e inovação em saúde, Programa Pesquisa para o SUS 
Gobernanza colaborativa para investigación en la salud: implicaciones del análisis del Programa de Investigación para el Sistema Único de Salud

Esta investigación busca analizar la gobernanza colaborativa en el contexto de la implementación del Programa de Pesquisa para SUS: Gestão Compartilhada em Saúde (PPSUS), en tres estados brasileños seleccionados, entre los años 2002 y 2016, utilizando el modelo teórico de Ansell y Gash (2008). Para lograr este objetivo, el estúdio utiliza método cualitativo, procedimientos de estudio de casos, así como recolección de datos a través de análisis de documentos y entrevistas de campo en los tres estados seleccionados. Concluye que el proceso de gobernanza colaborativa de PPSUS en los tres estados analizados es incompleto y que, a pesar del diseño colaborativo del programa y la existencia de decisiones conjuntas, la implementación de acciones está limitada por los recursos, el conocimiento y los procesos disponibles en cada organización que participa en el Programa. Esto significa que estos elementos influyen fuertemente en el proceso de colaboración, un hallazgo del cual se propone incluir en el modelo una categoría llamada "capacidad de gestión intraorganizacional".

Palabras clave: gobernanza colaborativa, tecnología e innovación en salud, Programa de Investigación para el SUS

Collaborative governance for research in health: implications from analysis of the Research Program for the Unified Health System

This research seeks to analyze collaborative governance in the scope of the Research Program for SUS: Shared Health Management (PPSUS), in three selected Brazilian states (Minas Gerais, Paraná e Sergipe), between the years 2002 and 2016, based on the theoretical model of Ansell and Gash (2008). To achieve this objective, the study uses a qualitative method, case study procedures, as well as data collection through documentary analysis and field interviews in the three selected states. It concludes that the process of collaborative governance within the scope of the PPSUS in the three analyzed states occurs in an incomplete way, dispite of the collaborative design of the program and the existence of joint decisions. The implementation of actions is limited by the resources, knowledge and processes available in each organization participating in the Program. This means that these elements strongly influence the collaborative process, a finding from which it is proposed to include in the model a category called "intraorganizational management capacity".

Keywords: collaborative governance, technology and innovation policy, Research for the Brazilian Unified Health System Program 


\section{Introdução}

A gestão através das fronteiras organizacionais é temática constante e relevante nos trabalhos de inúmeros teóricos da administração pública, desde suas origens na ciência política contemporânea. Articular atores - organizacionais e individuais - com distintos interesses, visando à consecução de um objetivo comum, é um desafio inevitável para qualquer um que se aventure na implementação de um programa ou de uma política pública.

Em que pese modelos de implementação de políticas públicas se preocuparem com a questão da interação entre os diferentes atores desde o nascedouro das pesquisas nesse campo, desenvolvimentos teóricos mais recentes (AGRANOFF; MCGUIRRE, 2003; AnSEll; GASH, 2008; TANG; MAZMANIAN, 2010; EMERSON; NABATCHI; BALOGH, 2012) têm buscado definir conceitos e sistematizar fatores que condicionam o resultado de um processo de interação, normalmente a partir de estudos de caso de políticas. Emerge, nesse arcabouço de estudos, o conceito de governança colaborativa, o qual, em linhas gerais, é definido como um arranjo decisório coletivo, que envolve agências governamentais e atores não governamentais, com o propósito de formular e implementar uma política pública ou gerenciar um programa com fins públicos, de maneira voluntária, em um processo construtivo, orientado para o consenso.

O imperativo da gestão interorganizacional é fundamental para a política pública de ciência, tecnologia e inovação. No que se refere à política de ciência e tecnologia específica para o setor saúde, Albuquerque e Cassiolato (2002) salientam o papel central do setor público no financiamento da pesquisa em saúde, tanto nos países desenvolvidos quanto nos países em desenvolvimento. Schwartzman (2002), por sua vez, destaca a relação direta entre o interesse público e a pesquisa em saúde. Conclui que essa é uma área de ponta se considerado o ambiente da pesquisa aplicada nacional, em termos do relacionamento entre a academia e o setor empresarial, assim como em termos do uso de conhecimentos resultantes de pesquisa científica para a implementação de políticas públicas, embora identifique alguns pontos problemáticos nessa articulação.

Em se tratando do caso brasileiro, impende destacar que o Sistema Único de Saúde (SUS) tem uma estrutura institucional complexa, desenhada a partir dos marcos da participação e da descentralização, o que torna a coordenação das ações dos três níveis de governo, bem como de provedores de serviços públicos e privados, um desafio 
(ARRETCHE, 2003). Guimarães (2004) argumenta que esse desenho institucional do SUS se reflete na área de pesquisa em saúde e advoga pela necessidade de maior articulação entre as agências federais - dotadas de maior disponibilidade de recursos -, bem como pela descentralização das ações, sobretudo na definição das prioridades da agenda de pesquisa em saúde.

Nesse contexto, encontra-se inserido o Programa "Pesquisa para o Sistema Único de Saúde: Gestão Compartilhada em Saúde” (PPSUS). Como o próprio nome indica, o programa visa à gestão compartilhada dos recursos disponíveis entre as agências federais e estaduais responsáveis pelas políticas de saúde e de ciência e tecnologia, com fins de promover a descentralização do esforço de pesquisa no campo da saúde e, dessa forma, aproximar o resultado dessas pesquisas das necessidades regionais do sistema de saúde.

Em suma, o programa é coordenado e financiado, majoritariamente, pelo Ministério da Saúde (MS) e executado por meio de um arranjo organizacional que envolve o Conselho Nacional de Desenvolvimento Científico e Tecnológico (CNPq), responsável por orientações gerais; as Fundações de Amparo à Pesquisa (FAP); e as Secretarias de Estado de Saúde (SES), que cumprem o papel de operadoras estaduais do programa. Além do objetivo de descentralizar os recursos e ações de pesquisa em saúde, o desenho do PPSUS conta com um modelo participativo de definição da agenda prioritária de pesquisa que envolve, além das agências governamentais citadas, os próprios pesquisadores e os gestores em saúde (BRASIL, 2014).

Considerando os objetivos e o referido modelo para formulação e implementação do PPSUS, no qual se forma uma rede de atores governamentais e não governamentais que interagem dinamicamente e no qual o compartilhamento de responsabilidades é elemento-chave, a interação colaborativa entre tais atores envolvidos é um pressuposto do seu sucesso. Em outras palavras, se não há colaboração entre os atores, não é possível supor que o programa alcance seus resultados pretendidos. Nesse sentido, a miríade de atores interagindo na implementação de uma política pública de pesquisa em saúde, o PPSUS, constitui-se objeto digno de ser estudado à luz dos recentes modelos de gestão pública, desenvolvidos sob a égide do conceito de governança colaborativa. 
A literatura a respeito da governança colaborativa procurou estabelecer frameworks - ou modelos - para relacionar construtos que estão ligados ao processo decisório colaborativo e permitir uma compreensão analítica do fenômeno. Entre os modelos desenvolvidos, esta pesquisa está baseada no modelo de Ansell e Gash (2008), segundo o qual os principais fatores relacionados ao processo colaborativo e seus resultados são: as condições iniciais de colaboração, compostas pelos incentivos e constrangimentos ao engajamento dos atores; o desenho institucional; o papel da liderança; e a construção de confiança.

A partir da constatação dos desafios para a condução de uma política pública de ciência e tecnologia em saúde, bem como considerando o desenvolvimento de modelos teóricos para a análise de arranjos colaborativos no setor público, as perguntas que orientam esta pesquisa são as seguintes: como ocorre a governança colaborativa no âmbito da implementação do Programa Pesquisa para o SUS em três estados brasileiros? Que implicações a análise desse caso empírico possui para o modelo teórico, em termos dos seus limites e potencialidades?

\section{Governança colaborativa}

A interação entre variados atores no processo de implementação de políticas públicas remete a conceitos recentemente adotados pela literatura em políticas públicas: os conceitos de "governança" e "colaboração". Segundo Emerson, Nabatchi e Balogh (2012), diversos autores tratam da temática "gestão através das fronteiras organizacionais" com diferentes enfoques, o que torna suas definições amplas e multifacetadas.

Martins e Marini (2014, p. 42) advertem que "governança pública é o termo do momento", por isso, primeiramente, é preciso delinear alguns de seus conceitos. Para Emerson, Nabatchi e Balogh (2012), governança, como um termo geral, se refere ao ato de governar, seja no setor privado ou público. Ainda, no sentido de clarear o conceito, os autores recorrem a Ostrom (1990), que considera governança como normas e regras definidas conjuntamente para regular os comportamentos individuais e $\mathrm{o}$ comportamento de grupo.

Para Stoker (1998), o termo governança se refere, em última instância, à criação das condições para implementar regras e viabilizar a própria ação coletiva. $\mathrm{O}$ autor 
argumenta que, apesar da variedade de significados assumidos pelo termo na literatura, existe uma concordância em relação ao fato de que governança está relacionada ao desenvolvimento de estilos de governar, nos quais os limites organizacionais não são muito claros. No mesmo sentido e tratando especificamente da governança pública, Peters e Pierre (1998) salientam que o termo está relacionado a formas de governar que envolvem redes, parcerias e mercados. Peci, Pieranti e Rodrigues (2014), por sua vez, definem a governança pública como um modelo de gestão pública que considera a fluidez nas fronteiras e nas relações de poder entre o Estado e o setor privado, incluído o terceiro setor.

McGuire (2006) sustenta que, embora a atenção conferida pela literatura à gestão colaborativa nos anos 2000 sugira que se trata de algo relacionado às práticas de gestão daquela década, há evidências suficientes para afirmar que gestores públicos praticam a gestão colaborativa há muito tempo. De acordo com o autor, a tradição de estudos a respeito da gestão intergovernamental, focada nas questões do federalismo (em especial o norte-americano), é um exemplo claro de que relações de natureza colaborativa são examinadas desde, pelo menos, os anos 1960. Os diferentes níveis de governo - assim como as organizações não governamentais sem fins lucrativos - têm cooperado por décadas, formal e informalmente, vertical e horizontalmente, de várias maneiras e por meio de inúmeros mecanismos, para a consecução de políticas públicas (MCGUIRE, 2006).

Ainda de acordo com McGuire (2006), o trabalho seminal de Pressman e Wildavsky (1973) a respeito da implementação de políticas públicas descreve, já nos anos 1970, a complexidade da gestão compartilhada, bem como a multiplicidade de participantes e suas perspectivas sobre os objetivos das políticas, sugerindo o caráter interativo da gestão pública. Não obstante, o surgimento do conceito de gestão pública colaborativa e o próprio interesse de acadêmicos pelo assunto é um fenômeno mais recente, o que, segundo McGuire (2006), pode ser explicado por duas perspectivas: de um lado, a era da informação deu origem a estruturas permeáveis e permite que pessoas estabeleçam elos por meio das funções organizacionais e suas fronteiras. De outro lado, os problemas e as questões que os governos enfrentam têm crescido em complexidade, devido à diversificação e especialização cada vez maiores da sociedade, o que extrapola 
a capacidade de ação das tradicionais organizações hierárquicas e requer estruturas colaborativas para sua resolução (MCGUIRE, 2006).

Agranoff e McGuire (2003) conceituam a gestão colaborativa como um arranjo organizativo intencionalmente desenhado para operar em um contexto multiorganizacional e resolver problemas que não poderiam ser resolvidos, ou facilmente resolvidos, por uma organização sozinha. Os autores ressaltam o caráter deliberado e estratégico desse modo de ação e, segundo eles, cabe aos governos decidirem, no âmbito de determinado contexto e considerando determinadas restrições, em que momento e em que seara de atuação eles colaboram ou não.

O’Leary e Vij (2012) realizam uma revisão dos estudos concernentes à gestão pública colaborativa e concluem que se trata de um campo de pesquisa não paradigmático, devido a fatores como a falta de acordo sobre o significado da própria palavra colaboração, baixo consenso sobre os tópicos relevantes de pesquisa, fundamentação em narrativas anedóticas, bem como a adoção de diferentes e incompletas unidades de análise.

Feitas considerações a respeito dos termos "governança pública" e "gestão pública colaborativa", apresentam-se as origens e conceitos da expressão governança colaborativa. Conforme Ansell e Gash (2008), o caráter desordenado da literatura a respeito do tema reflete o modo como os estudos nesse campo surgiram, a partir de vários experimentos práticos locais, como resposta às falhas dos modelos de implementação anteriores. Os autores argumentam que a abordagem da governança colaborativa surgiu como alternativa tanto às falhas de accountability do modelo gerencialista quanto ao modelo baseado no conflito entre grupos de interesses plurais (pluralismo ou adversarialismo), comumente adotados para estudos sobre a formulação e implementação de políticas públicas (ANSELL; GASH, 2008).

Emerson, Nabatchi e Balogh (2012) identificaram as origens teóricas e práticas da governança colaborativa da seguinte maneira: em termos de teoria, a abordagem tem uma de suas raízes nos estudos de relações intergovernamentais e no próprio nascimento do federalismo americano. Para os autores, o desenvolvimento do conceito tem ainda conexão com a extensa literatura a respeito da lógica da ação coletiva e do problema da produção de bens comuns, tal como desenvolvida por Ostrom (1990) no âmbito da economia institucional. Fundamentados nessa abordagem, Tang e Mazmanian (2010) 
argumentam que a governança colaborativa emergiu como uma forma institucional chave para o provimento de serviços e bens públicos, tanto na esfera acadêmica quanto na profissional da administração pública, e perpassa inúmeras arenas de política, tais como meio ambiente, infraestrutura, desenvolvimento social e saúde.

Do ponto de vista prático, governança colaborativa tem relação com modelos de gestão construídos a partir das interfaces entre organizações. Kettl (2006) observa que há um imperativo da colaboração, isto é, alcançar resultados efetivos através das fronteiras organizacionais requer novas estratégias e novas habilidades por parte dos gestores públicos. O desenvolvimento dessas práticas - especialmente em nível local, conforme examinam Agranoff e McGuire (2003) - é algo reconhecido e estudado como um novo fenômeno: a governança colaborativa (EMERSON; NABATCHI; BALOGH, 2012). No mesmo sentido, Tang e Mazmanian (2010) ressaltam que, em termos de governança colaborativa, a prática precede à teoria e se conhece mais a respeito de casos particulares do que se formulou explicações amplas a respeito das condições de sua emergência e viabilidade.

Emerson, Nabatchi e Balogh (2012) definem governança colaborativa de um modo reconhecidamente abrangente com o fim de abarcar diferentes aplicações, classes e escalas para o conceito:

The processes and structures of public policy decision making and management that engage people constructively across the boundaries of public agencies, levels of government, and/or the public, private and civic spheres in order to carry out a public purpose that could not otherwise be accomplished (NABATCHI; BALOGH, 2012, p. 2). ${ }^{1}$

Por sua vez, Tang e Mazmanian (2010) definem o termo como

[...] a concept that describes the process of establishing, steering, facilitating, operating, and monitoring cross-sectoral organizational arrangements to address public policy problems that cannot be easily addressed by a single organization or the public sector alone. These arrangements are characterized by joint efforts, reciprocal expectations, and voluntary participation among formally autonomous entities, from two or more sector - public, for profit,

\footnotetext{
${ }^{1}$ Processos e estruturas de gestão e tomada de decisão em políticas públicas que engajam pessoas de maneira construtiva através das fronteiras das agências públicas, níveis de governo e/ou esferas públicas, privadas e civis, no sentido de alcançar um propósito público que não poderia ser alcançado de outra forma (tradução dos autores deste trabalho).
} 
and nonprofits - in order to leverage (build on) the unique attributes and resources of each (TANG; MAZMANIAN, 2010, p. 4) $)^{2}$.

A principal diferença que se observa entre essas duas definições diz respeito ao direcionador (driver) do arranjo colaborativo. Ambas concordam em relação ao objetivo de resolução de problemas complexos e multifacetados. No entanto, seguindo a tradição da escolha racional, típica da economia institucional, Tang e Mazmanian (2010) acrescentam como direcionador da ação conjunta a ideia de alavancagem de recursos exclusivos, mirando para o ponto de vista de cada organização individualmente e sua estratégia e ressaltando o caráter deliberado da ação colaborativa.

Finalmente, Ansell e Gash (2008) apresentam uma definição mais restritiva em relação às anteriormente colocadas para governança colaborativa, a que é utilizada neste trabalho, qual seja:

A governing arrangement where one or more public agencies directly engage non-state stakeholders in a collective decision-making process that is formal, consensus-oriented, and deliberative and that aims to make or implement public policy or manage public programs or assets (ANSELL; GASH, 2008, p. $544){ }^{3}$

Essa definição apresenta critérios relevantes, os quais divergem ou restringem alguns aspectos dos conceitos desenvolvidos por Emerson, Nabatchi e Balogh (2012) e por Tang e Mazmanian (2010): (a) o fórum é iniciado pelo governo; (b) o fórum inclui entidades não governamentais; (c) participantes se engajam na tomada de decisões e não são meramente consultados; (d) o fórum é formalmente organizado; (e) o fórum visa ao consenso (mesmo que o consenso nem sempre seja alcançado); (f) o foco do fórum está sobre a gestão da política pública (ANSELL; GASH, 2008).

Definido, portanto, o conceito de governança colaborativa adotado para esta pesquisa, a saber, o de Ansell e Gash (2008), avança-se para a apresentação do modelo desenvolvido pelos autores a partir de uma meta-análise envolvendo 137 estudos de caso de processos colaborativos registrados na literatura, os quais, obviamente, atendem

\footnotetext{
${ }^{2}$ Um conceito que descreve o processo de estabelecer, dirigir, facilitar, operar e monitorar arranjos organizacionais intersetoriais para tratar de problemas de políticas públicas que não podem ser facilmente abordados por uma única organização ou o setor público por si só. Esses arranjos se caracterizam por esforços conjuntos, expectativas recíprocas e participação voluntária entre entidades formalmente autônomas, de dois ou mais setores - público, empresarial e sem fins lucrativos - visando alavancar os atributos e recursos exclusivos de cada um. (Tradução dos autores deste trabalho).

3 Arranjo administrativo governamental no qual uma ou mais agências públicas engajam atores não estatais diretamente em um processo de tomada de decisão coletiva que é formal, orientado para o consenso e deliberativo, visando elaborar ou implementar políticas públicas, ou gerenciar programas ou ativos públicos. (Tradução dos autores deste trabalho).
} 
às características inerentes ao conceito elaborado e definido anteriormente. Outros modelos teóricos para relacionar fatores com o objetivo de compreender a governança colaborativa foram desenvolvidos no âmbito da literatura apresentada, dentre os quais cabe destacar aquele proposto por Emerson, Nabatchi e Balogh (2012), autores que referenciam e dialogam com o modelo de Ansell e Gash (2008). Os motivos pelos quais esse último modelo foi o selecionado para a análise do objeto desta pesquisa, em detrimento de outros, são:

a) o conceito de governança colaborativa do qual ele parte, mais restritivo, decorre de uma perspectiva de ação governamental e, portanto, adequado ao objeto de estudo da pesquisa;

b) o fato de que apresenta menos categorias de análise em relação aos demais modelos analisados, atendendo, dessa forma, ao princípio científico da parcimônia, isto é, ao imperativo de adotar modelos mais simples entre aqueles que explicam o mesmo fenômeno (CRESWELL, 2007).

Ansell e Gash (2008) identificaram quatro macrofatores que definem os resultados de um processo colaborativo: condições iniciais, desenho institucional, liderança facilitadora e o próprio processo colaborativo. A Figura 1 sintetiza o referido modelo. 
Figura 1 - Modelo de governança colaborativa

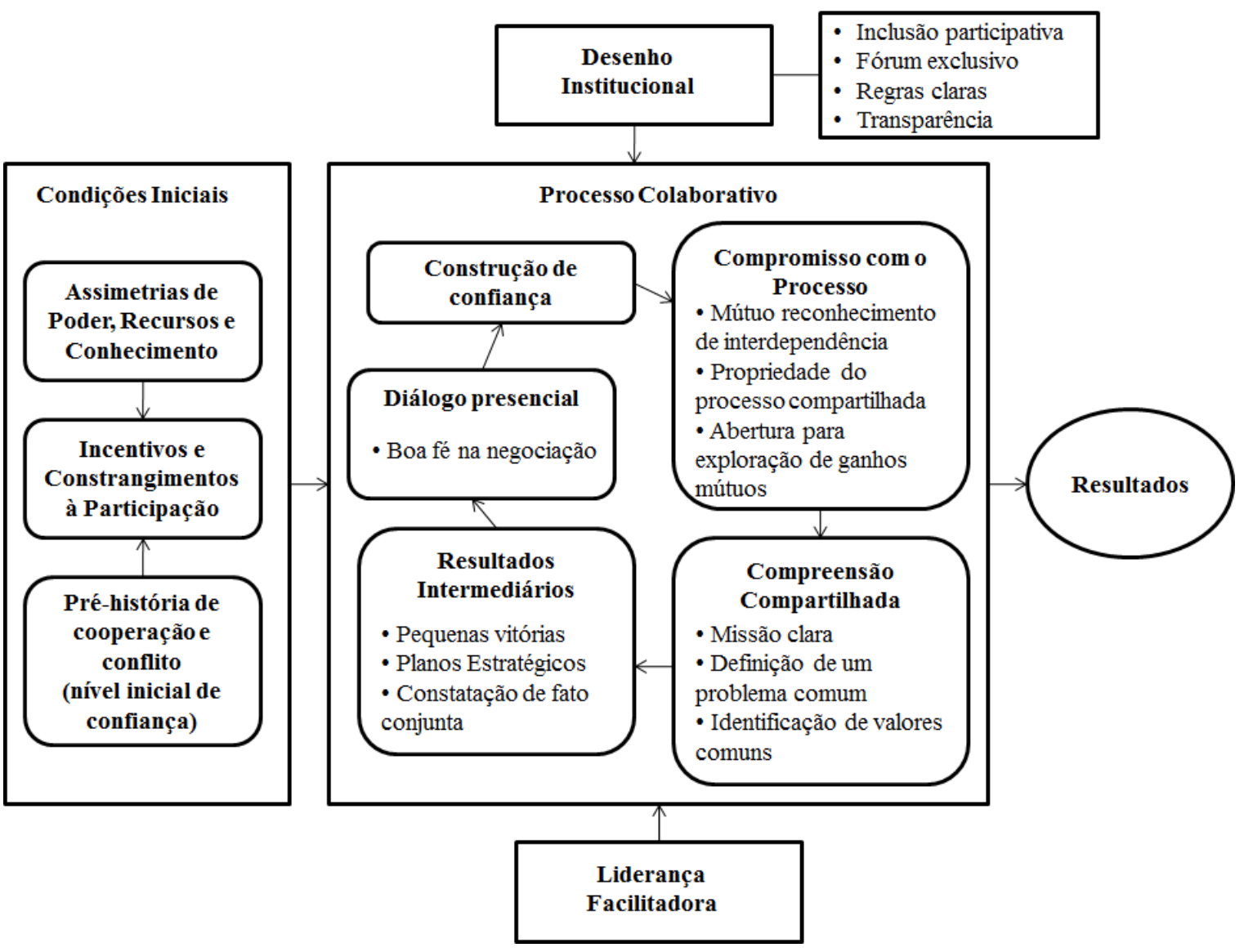

Fonte: Ansell e Gash (2008, p.550), adaptada pelos autores deste estudo.

O macrofator condições iniciais se refere ao nível de confiança entre os atores, ao grau de conflito e às assimetrias de conhecimento, recursos e poder, anteriores ao início do processo colaborativo. Apesar de abordagens colaborativas no sentido de resolver problemas públicos serem frequentemente mandatórias, legal ou judicialmente, a participação de modo colaborativo por parte de cada ator é voluntária, o que demanda uma análise dos incentivos ao engajamento dos atores, sejam eles positivos ou negativos. Além disso, a existência de arenas alternativas para a resolução unilateral do problema ou eventual histórico de conflito entre as partes envolvidas pode constranger ou minar o disparo de um processo colaborativo, a menos que os atores reconheçam sua interdependência. Essa constatação leva à necessidade de se ter em conta, na análise, o grau de interdependência percebido pelos atores (ANSELL; GASH, 2008).

Liderança facilitadora pode ser entendida como a atuação de um dos atores como mediador das mesas de negociação e trata-se de um ingrediente fundamental do modelo. Liderança é crucial para manter regras claras, construir confiança, facilitar o 
diálogo e explorar ganhos mútuos. No entanto, ela varia de acordo com o contexto da colaboração: ela pode ser profissional, no sentido de ser um mediador neutro, dotado da confiança dos demais envolvidos, sobretudo em casos em que o grau de conflito é elevado; e pode ser orgânica, isto é, emergir da própria comunidade de atores envolvidos, sobretudo quando há assimetrias de poder e a colaboração demanda a atuação de um líder forte que consiga congregar os demais em torno dos objetivos comuns (ANSELL; GASH, 2008).

Desenho institucional está relacionado às regras e aos protocolos que governam o processo colaborativo, o que é crítico no sentido de legitimar o processo colaborativo (AnSEll; GASH, 2008). Pontos relevantes de serem avaliados no contexto do desenho institucional são: a definição dos papéis, as regras para alcance do consenso e a delimitação de prazos e cronogramas (ANSELL; GASH, 2008).

Finalizando os macrofatores do modelo, o próprio processo colaborativo é definido como iterativo e não linear (ANSELl; GASH, 2008; EMERSON; NABATCHI; BALOGH, 2012). Esse processo tem como elemento identificado o diálogo face a face entre os envolvidos como condição necessária, mas não suficiente para colaboração. Pressupõe igualmente a construção de confiança, o que só é possível mediante dispêndio de tempo, isto é, relações de longo prazo. Pressupõe ainda compromisso com o processo, por meio do reconhecimento mútuo da interdependência entre os envolvidos, do compartilhamento de responsabilidades e da abertura para explorar ganhos mútuos. Mesmo quando a governança colaborativa é imposta pelas regras, a adesão continua sendo um elemento fundamental (ANSELL; GASH, 2008).

Outro componente do processo colaborativo é o entendimento compartilhado. Tal componente tem a ver com o caráter interpessoal das relações em uma arena de governança colaborativa e com a construção de objetivos e valores e estratégias comuns. O último componente do processo colaborativo a ser delineado são os resultados intermediários. Eles se referem às pequenas vitórias, ao alcance de resultados concretos que não sejam propriamente os objetivos finais do processo colaborativo. Sua existência (ou identificação) é particularmente crucial quando se consideram situações em que os objetivos finais da colaboração são de longo prazo e/ou situações em que há um elevado grau de conflito no início do processo e, consequentemente, o tempo tornase fundamental para a construção de confiança (ANSELL; GASH, 2008). 


\section{Programa Pesquisa para o SUS}

Criado em 2002 - e fortalecido em 2004, por meio da formalização da parceria entre o Ministério da Saúde (MS) e o Ministério da Ciência, Tecnologia e Inovação (MCTI - nome e sigla naquele momento) -, o Programa Pesquisa para o SUS visa contribuir para o incremento científico e tecnológico em saúde no país e para a redução das desigualdades regionais nesse campo. Mais além, o programa visa ainda aproximar a pesquisa da gestão do sistema de saúde, criando um canal para que os resultados da investigação científica subsidiem as decisões de políticas públicas e, consequentemente, potencializem a utilização dos recursos destinados à saúde (BRASIL, 2014).

O PPSUS envolve parcerias no âmbito federal e estadual, entre instâncias de saúde e de ciência e tecnologia. No nível federal, participam o [Ministério da Saúde] MS, coordenador nacional do Programa, e o CNPq [Conselho Nacional de Desenvolvimento Científico e Tecnológico], instituição responsável pelo gerenciamento administrativo do PPSUS. Na esfera estadual, estão envolvidas as Fundações de Amparo e/ou Apoio à Pesquisa (FAP), as Secretarias Estaduais de Saúde (SES) e as Secretarias Estaduais de Ciência e Tecnologia. [...] O PPSUS é uma iniciativa inovadora por adotar um modelo de gestão descentralizado e participativo, envolvendo diversos atores: gestores, profissionais de saúde, pesquisadores e representantes da sociedade civil organizada (BRASIL, 2014, p. 7).

A operacionalização do programa ocorre por meio da transferência de recursos do MS ao CNPq, que, por sua vez, firma convênio com as FAP. As FAP, em parceria com as SES, publicam as chamadas para seleção de projetos de pesquisa segundo os temas relevantes definidos regionalmente (BRASIL, 2011).

O desenvolvimento do PPSUS envolve nove etapas distintas: (1) realização de oficinas para seleção das prioridades de pesquisa em saúde, (2) elaboração e publicação da chamada, (3) submissão das propostas, (4) enquadramento das propostas, (5) avaliação ad hoc, (6) análise pela Comissão de Especialistas, (7) aprovação final pelo Comitê Gestor, (8) acompanhamento e avaliação das pesquisas e (9) análise do potencial e incentivo à incorporação dos resultados das pesquisas nos serviços de saúde (BRASIL, 2014, p. 9).

A Figura 2 apresenta esquematicamente o ciclo do PPSUS, relacionando as etapas de execução (cada qual acompanhada do seu número de identificação na enumeração transcrita acima) e os atores envolvidos em cada uma delas. 
Figura 2 - Fluxograma representativo do modelo de operacionalização do PPSUS

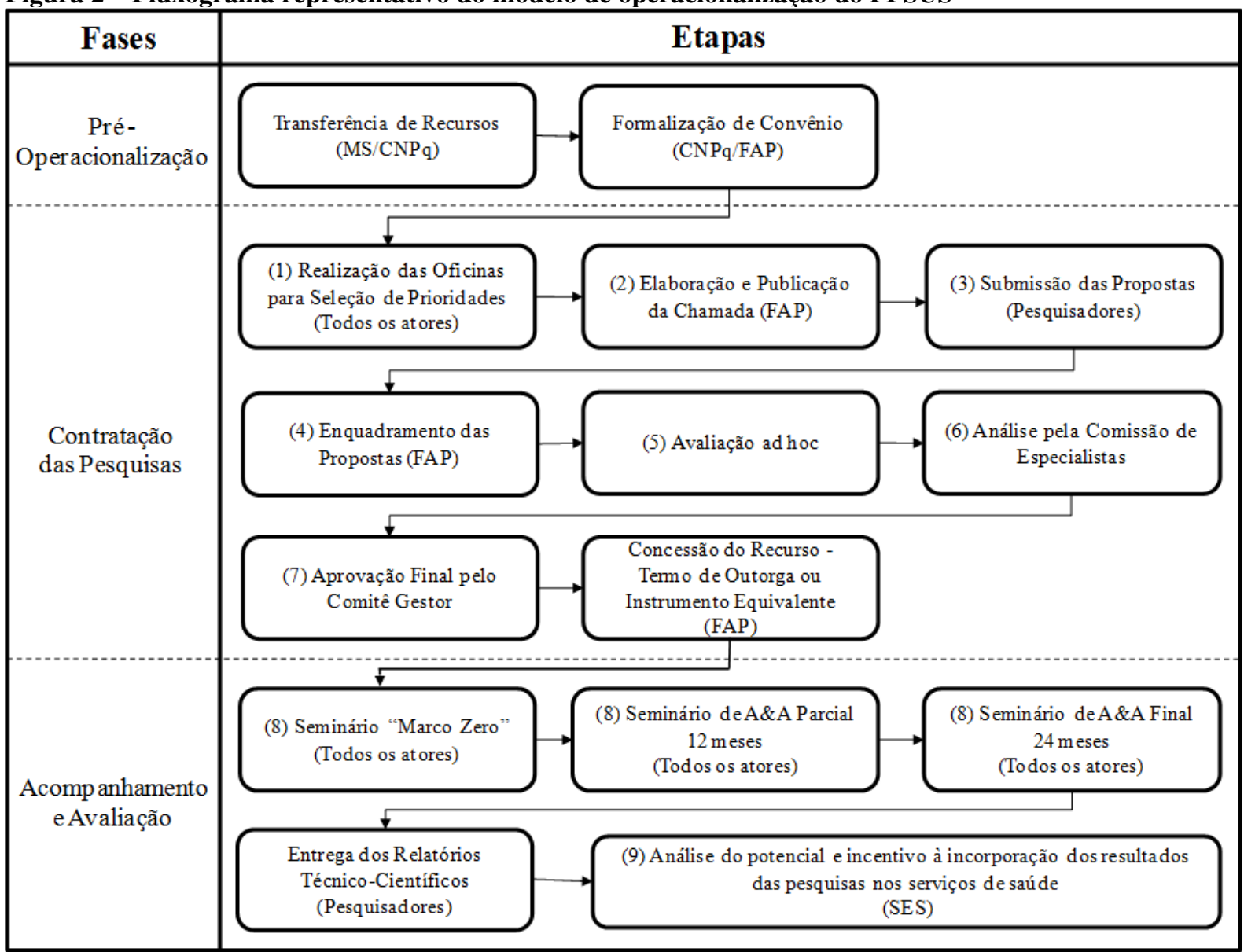

Fonte: elaborada pelos autores deste estudo a partir de Brasil (2014).

A fim de clarificar o ciclo de execução do PPSUS, faz-se necessário aprofundar em alguns passos prescritos nos manuais do programa, em especial nos eventos de trabalho que reúnem, presencialmente, mais de um dos atores envolvidos na gestão e operacionalização do programa. Primeiramente, as oficinas para seleção de prioridades (passo 1) são eventos de trabalho coordenados pelas SES, com apoio das FAP, envolvendo gestores do sistema de saúde, pesquisadores e representantes do controle social. Delas devem resultar as linhas temáticas, as quais devem estar baseadas nas necessidades regionais de saúde, que vão compor o edital para financiamento das pesquisas. Para esse evento do ciclo do programa, foram desenvolvidos instrumentos e manuais específicos, visando informar o processo de construção do consenso em torno dessa agenda prioritária de pesquisa (BRASIL, 2014).

Em seguida, vale destacar que a comissão de especialistas, responsável por analisar os projetos de pesquisa no passo 6 , deve ser composta tanto por pesquisadores com experiência comprovada nas áreas dos projetos submetidos quanto representantes 
das SES. O objetivo dessa análise, fundamentada na análise de mérito científico feita no passo 5 por pareceristas ad hoc e em parâmetros predefinidos e padronizados nacionalmente, é o de recomendar ou não a aprovação dos projetos. Realizada a aprovação dos projetos por parte do Comitê Gestor do PPSUS (passo 7) - o qual é composto, paritariamente, por membros do MS, do CNPq, da FAP e da SES - e a contratação/formalização do financiamento das pesquisas, inicia-se a fase de acompanhamento e avaliação (passo 8), com três eventos principais (BRASIL, 2014).

O seminário marco zero deve ser realizado antes do início das pesquisas e deve contar com a participação dos membros da comissão de especialistas e, obviamente, os pesquisadores responsáveis por cada projeto de pesquisa aprovado, com o fito de discutir ajustes metodológicos, entre outras contribuições e sugestões feitas no processo de julgamento das propostas de pesquisas. Os seminários de acompanhamento e avaliação parcial e final têm por objetivos: (a) apresentar os resultados/produtos alcançados; (b) aproximar os grupos de pesquisas envolvidos no programa e as áreas técnicas da SES; e (c) promover o diálogo em torno dos principais problemas de saúde da população do estado (BRASIL, 2014).

\section{Métodos e técnicas de pesquisa}

Esta pesquisa caracteriza-se, quanto aos objetivos, como uma pesquisa descritiva. Trata-se, ademais, de uma pesquisa de cunho qualitativo, isto é, adota uma abordagem que busca profundidade na análise de um caso específico de governança colaborativa para implementação de política pública - o PPSUS - em três estados brasileiros selecionados. Dessa feita, quanto aos procedimentos, a pesquisa caracterizase como um estudo de caso (CRESWELL, 2007).

A unidade de análise da pesquisa constitui-se no Programa Pesquisa para o SUS, em três estados brasileiros: Minas Gerais, Paraná e Sergipe. Esses estados foram selecionados conforme os seguintes critérios:

a) pesquisa exploratória identificou que os três estados apresentam arranjos organizacionais peculiares para a implementação do programa;

b) distribuição dos estados em macrorregiões distintas do país - abarcando Sudeste, Sul e Nordeste -, o que permite inferências mais sólidas, embora não estatisticamente generalizáveis, no tocante à análise das similitudes e diferenças 
regionais da implementação do programa, especialmente considerada sua abrangência nacional;

c) disponibilidade de agenda dos atores relevantes selecionados para a realização das entrevistas.

Visando delimitar, não apenas programática e geograficamente as fronteiras da unidade de análise, faz-se necessário delimitar o período de tempo: o recorte temporal selecionado, entre 2002 (ano de criação do programa) e 2016 (ano de realização das entrevistas), refere-se a um período de 14 anos que compreende seis ciclos de execução do programa nos Estados de Minas Gerais e Paraná, bem como quatro ciclos de execução no Estado de Sergipe. Ciclo de execução aqui entendido nos termos descritos na seção 3, isto é, a realização de todas as etapas do programa, desde a seleção das prioridades de pesquisa até a análise do potencial e incentivo à incorporação dos resultados das pesquisas nos serviços de saúde.

O estudo utilizou análise documental e entrevista. Os documentos utilizados como fontes para a pesquisa consistem nos manuais, relatórios e formulários produzidos no âmbito da gestão do PPSUS. As entrevistas foram realizadas com os gestores do PPSUS nas agências estaduais de fomento à pesquisa e à inovação científica e tecnológica, isto é, as Fundações de Amparo à Pesquisa (FAP) - ou organizações equivalentes - e nas Secretarias Estaduais de Saúde (SES) dos estados selecionados. Foram selecionados profissionais que ocupam cargos relacionados à execução do programa nas organizações responsáveis por sua implementação em âmbito regional, configurando-se como atores-chave, os quais atuam diretamente na dinâmica colaborativa de realização do programa em seus respectivos territórios de jurisdição. $\mathrm{O}$ Quadro 1 sintetiza alguns dados dos entrevistados, com o fito de evidenciar a sua relevância enquanto sujeitos da implementação do programa e, consequentemente, informantes adequados aos objetivos desta pesquisa. 


\section{Quadro 1 - Quadro de entrevistados}

\begin{tabular}{|c|c|c|c|c|}
\hline Identificação & Estado & Organização & $\begin{array}{l}\text { Unidade de } \\
\text { Exercício }\end{array}$ & $\begin{array}{c}\text { Tempo } \\
\text { na } \\
\text { Função } \\
\end{array}$ \\
\hline A & \multirow[b]{2}{*}{ SE } & $\begin{array}{l}\text { Secretaria de Estado de Saúde } \\
\text { de Sergipe }\end{array}$ & $\begin{array}{l}\text { Coordenação de } \\
\text { Educação } \\
\text { Permanente }\end{array}$ & 5,0 anos \\
\hline B & & $\begin{array}{l}\text { Fundação de Apoio à Pesquisa } \\
\text { e à Inovação Tecnológica do } \\
\text { Estado de Sergipe }\end{array}$ & $\begin{array}{l}\text { Coordenação do } \\
\text { Programa de } \\
\text { Inovação } \\
\text { Tecnológica }\end{array}$ & 7,0 anos \\
\hline $\mathrm{C}$ & \multirow[t]{2}{*}{ MG } & $\begin{array}{l}\text { Fundação de Amparo à } \\
\text { Pesquisa do Estado de Minas } \\
\text { Gerais }\end{array}$ & $\begin{array}{l}\text { Escritório de } \\
\text { Gerenciamento de } \\
\text { Parcerias }\end{array}$ & 8,0 anos \\
\hline $\mathrm{D}$ & & $\begin{array}{l}\text { Secretaria de Estado de Saúde } \\
\text { de Minas Gerais }\end{array}$ & $\begin{array}{l}\text { Assessoria de } \\
\text { Planejamento }\end{array}$ & 4,0 anos \\
\hline $\mathrm{E}$ & \multirow{4}{*}{ PR } & \multirow{3}{*}{ Fundação Araucária } & $\begin{array}{l}\text { Diretoria } \\
\text { Científica }\end{array}$ & 1,5 anos \\
\hline $\mathrm{F}$ & & & $\begin{array}{l}\text { Assessoria } \\
\text { Científica } \\
\end{array}$ & 3,0 anos \\
\hline G & & & Setor de Projetos & 9,0 anos \\
\hline $\mathrm{H}$ & & $\begin{array}{l}\text { Secretaria de Estado de Saúde } \\
\text { do Paraná }\end{array}$ & $\begin{array}{l}\text { Escola de Saúde } \\
\text { Pública do Paraná }\end{array}$ & 5,0 anos \\
\hline
\end{tabular}

Fonte: elaborado pelos autores deste estudo.

O tempo em que cada um dos entrevistados exerce a função de gestor do PPSUS demonstra que boa parte dos respondentes passou por mais de um ciclo de execução do programa, o que lhes permite fornecer informações históricas. As entrevistas foram semiestruturadas, ou seja, contaram com um roteiro constituído por categorias previamente definidas, seguindo o modelo de análise proveniente da literatura.

A análise dos dados foi feita mediante análise de conteúdo das entrevistas e da documentação, codificando os principais elementos identificados nas respostas de cada um dos entrevistados, bem como na documentação analisada, a partir das categorias previamente estabelecidas na literatura. A análise do conteúdo se deu a partir de uma abordagem qualitativa, preservando a forma literal dos dados obtidos, em contraposição à fragmentação de análises numéricas e estatísticas da frequência de expressões, com vistas a observar e compreender o sentido, os elos lógicos entre os elementos do texto. A estratégia adotada para tanto se baseou no emparelhamento ou justaposição das unidades de conteúdo às categorias de modelo teórico, com a finalidade de compará-los e, daí fazer inferências (LAVILLE; DiONNE, 1999). 
Bardin (1979) afirma que, na análise de conteúdo, o conhecimento é inferido a partir de indicadores, isto é, vestígios presentes nas mensagens. Para a autora, a descrição dos elementos do conteúdo não tem outro objetivo, senão a determinação das condições de produção da mensagem, ou seja, a inferência de variáveis sociológicas, psicológicas, entre outras, subjacentes ao indivíduo que profere determinados enunciados. O processo inferencial visa, portanto, interpretar, estabelecer os fatores que determinaram as características do conteúdo descrito e analisado em uma fase antecedente (BARDIN, 1979).

\section{Apresentação e análise dos resultados}

\subsection{Condições iniciais}

Em relação às condições iniciais da colaboração entre os atores envolvidos, é relevante destacar que, antes da criação do PPSUS, a pesquisa em saúde, nos três estados analisados, era fomentada no âmbito de iniciativas gerais de fomento à ciência e tecnologia, sem um direcionamento específico, conforme se pode observar nas falas dos entrevistados, exemplificadas pela fala do responde transcrita a seguir.

A pesquisa em saúde era sempre voltada para o nosso edital de pesquisa básica e aplicada, que daí incluía todas as grandes áreas: agrária, saúde, biológicas, exatas. Então, era focada mais na nossa pesquisa mesmo, não tinha um edital voltado especificamente para saúde (Entrevistado H - FAP).

O estabelecimento de um Termo de Cooperação e Assistência Técnica entre o MS e o MCTI, em 2004, é um marco fundamental no contexto de criação e fortalecimento do PPSUS, conforme se observa no manual de diretrizes técnicas do programa. Isso implica a existência de incentivos institucionais positivos à colaboração implícitos no próprio desenho do programa.

No tocante ao reconhecimento da interdependência por parte dos atores, nota-se uma discrepância entre o entendimento dos respondentes das FAP e das SES, com exceção do Estado do Paraná. Via de regra, os gestores das FAP reconhecem a forte interdependência que sua atuação tem em relação ao papel definidor das prioridades de agenda de pesquisa, que é das secretarias estaduais de saúde. Mais especificamente, eles entendem a secretaria como uma espécie de cliente a ser atendido, conforme o argumento - exemplificativo - do entrevistado a seguir. 
Foi de grande valia para a Fundação, porque é um programa exclusivo para área da saúde, é um programa que vem atendendo às demandas da Secretaria. Então a gente criou um vínculo com a Secretaria que não existia, porque a gente normalmente tem um vínculo com o pesquisador, com a instituição acadêmica (Entrevistado B - FAP).

Por sua vez, os respondentes das SES, conforme exemplificado pela fala transcrita a seguir, admitem que os gestores da secretaria conferem pouca importância ao programa, denotando a ausência de percepção desses atores quanto a potenciais benefícios da ação conjunta.

A adesão ao PPSUS dentro da Secretaria de Estado da Saúde em relação às áreas, aos técnicos, aos especialistas, é muito difícil. Eles encaram como mais uma coisa a fazer. Então, não é fácil não, a mobilização das áreas é o grande desafio dessa agenda (Entrevistado A - SES).

A exceção nesse item de análise é o Estado do Paraná, cujo arranjo organizacional específico, distinto dos dois outros estados analisados, prevê a atuação da sua Escola de Saúde Pública na definição da agenda de pesquisa, o que pode ser um fator que explica a evidência da maior aceitação do programa por parte dos atores do sistema de saúde, se comparados aos atores do sistema de saúde dos outros dois estados.

Em suma, a análise das condições iniciais do programa identificou que os instrumentos normativos, criados em âmbito federal, constituem incentivos positivos à governança colaborativa do PPSUS, podendo ser considerados como um direcionador (driver) - no termo de Emerson, Nabatchi e Balogh (2012) - do processo colaborativo. Esse incentivo produziu os efeitos desejados nos atores FAP, os quais reconhecem os benefícios da ação conjunta com as SES no âmbito do programa. No entanto, não foi capaz de produzir o mesmo efeito no outro lado da arena de governança do programa: o lado das SES.

\subsection{Liderança facilitadora}

O desenho do PPSUS prevê a execução propriamente dita do programa como responsabilidade das agências estaduais (FAP e SES), cabendo a esses atores a liderança do processo colaborativo. Isso significa que o processo pode ter diferentes graus de desempenho, dependendo do desempenho dos atores regionais. $\mathrm{O}$ que se observa a partir da análise das falas dos entrevistados é que há, de fato, heterogeneidade em aspectos operacionais do programa, tal como a logística de organização dos eventos nas várias fases de execução de um ciclo. Não obstante, de maneira geral, nota-se um 
padrão de divisão de responsabilidades, qual seja: a mobilização da academia é realizada pelas FAP e a mobilização dos gestores do sistema de saúde é feita pelas SES, de modo que cada entidade segue cumprindo seu papel organizacional tradicional, não havendo um intercâmbio de responsabilidades e não sendo perceptível a nítida liderança de um desses atores no processo.

A gente tem feito a divulgação e a convocação de toda a comunidade cientifica para participação e discussão desses temas. A fundação tem sempre direcionado o chamamento à comunidade acadêmica (Entrevistado G - FAP).

A gente fica mais com esse contato interno de achar internamente quem são as pessoas estratégicas para participar. A gente tenta utilizar a FAP para o contato acadêmico e a gente fica mais com essa indicação dos gestores (Entrevistado D - SES).

Esse contato com o pesquisador é competência da Fundação, o papel das Secretarias de Estado é elencar quais são as linhas de pesquisas, os temas, então essa é a nossa função (Entrevistado H - SES).

Diante dessas evidências, o que se percebe é que há um vácuo de liderança na condução da arena colaborativa. Cada ator se limita à sua competência legal ou estatutária e não age no sentido de mediar o debate entre academia e gestores do sistema de saúde.

\subsection{Desenho institucional}

As regras que governam a execução do PPSUS claramente incentivam a colaboração entre os diversos atores envolvidos, com destaque para a institucionalidade dos eventos (fóruns) destinados à seleção da agenda prioritária de pesquisa, à avaliação ex-ante da adequação das propostas de pesquisa, ao monitoramento e avaliação final dos resultados das pesquisas (BRASIL, 2014). O manual de diretrizes do programa define as responsabilidades de cada um dos atores, salientando-se o fato de que várias das atividades são de responsabilidade conjunta das FAP e das SES (BRASIL, 2014).

No mesmo sentido, encontram-se previstas regras para a realização de todas as fases do ciclo, tais como prazos para várias das atividades elencadas em cada uma dessas fases. As regras contemplam ainda os critérios para alcance do consenso, isto é, para a seleção das prioridades de pesquisa, assim como para a seleção e a avaliação dos projetos de pesquisa (BRASIL, 2014).

No que se refere à percepção dos gestores em relação ao desenho institucional do programa, observa-se que todos eles apontam no sentido de que as regras favorecem 
a colaboração, mas, em alguns casos, esses entrevistados reconhecem limitações e potencial de melhorias, de ordens diversas, tais como as regras de elegibilidade para recebimento de recursos do programa e relacionadas ao monitoramento das pesquisas.

Outro aspecto relevante para a análise do desenho institucional, apontado por Emerson, Nabatchi e Balogh (2012), é a forma que as estruturas colaborativas podem assumir, considerando as relações interorganizacionais. Dado que as regras do programa não preveem a criação de uma entidade específica para a sua gestão, depreende-se que o objetivo do desenho do programa é que a arena colaborativa seja autogerida. Retomada a constatação do vácuo de liderança evidenciado na subseção anterior, tem-se o entendimento de que a (auto)gestão da arena colaborativa é algo incipiente e os participantes estão voltados para suas próprias e tradicionais competências.

\subsection{Processo colaborativo}

Em relação ao diálogo face a face, pressuposto para que haja construção de confiança e, consequentemente, um processo colaborativo, há a previsão de fóruns e eventos presenciais que garantem o diálogo presencial entre os atores, conforme constatado na própria descrição do programa e na seara de seu desenho institucional. Tal situação prevista nos normativos é percebida na implementação do programa pelos atores entrevistados, os quais descrevem a participação dos gestores do sistema de saúde e dos pesquisadores em saúde nos fóruns colaborativos, bem como, em alguns casos, reconhecem a importância dessa participação.

No tocante ao compromisso com o processo, nota-se que são seguidos os ritos burocráticos, mas não há efetividade nesse compromisso. A interpretação de que esse compromisso não é efetivo se deve ao fato de que as FAP entendem que a aplicabilidade dos resultados das pesquisas desenvolvidas mediante recursos do PPSUS, isto é, a consecução do seu objetivo final, é de responsabilidade das SES. Por sua vez, as SES reconhecem que, muitas vezes, o produto recebido no âmbito do programa não tem aplicabilidade ou apresenta baixa aplicabilidade no sistema.

Depois que a gente encerra o convênio, fica a cargo da Secretaria fazer o acompanhamento e fazer essa aplicabilidade (Entrevistado B - FAP).

Essa questão a própria Saúde poderia responder com mais propriedade. Daí adiante demanda uma provocação da saúde no sentido de ver o quanto isso tem sido aplicado ou não. A gente não tem o instrumental para isso (Entrevistado E - FAP). 
A gente não tem também esse acesso às unidades, a gente não tem acesso ao trabalho executado dentro das unidades de saúde, dentro das áreas de saúde (Entrevistado F - FAP).

Essa é a grande dificuldade de adesão porque é a grande queixa dos especialistas. Então, esses trabalhos, a aplicabilidade deles para o SUS é questionável (Entrevistado A - SES).

Então, a gente até questionava: quem é o cliente do PPSUS? É a SES ou são os pesquisadores? E isso, muitas vezes, eu vou fazer uma pesquisa que não tem interesse para o SUS em si, mas interesse do pesquisador (Entrevistado $\mathrm{D}-\mathrm{SES})$.

Depreende-se, considerando os trechos acima transcritos, que o entendimento compartilhado em relação aos objetivos do PPSUS e à missão comum das agências públicas envolvidas no programa é algo que está em construção e, conforme descrito pela literatura, é algo que carece de tempo, de relações de longo prazo (ANSELL; GASH, 2008).

Nota-se, ademais, que há um evidente conflito de interesses entre pesquisadores e gestores quanto às prioridades de pesquisa: via de regra, pesquisadores tendem a direcionar os recursos e esforços do programa para suas temáticas afins e não necessariamente esse é o interesse dos gestores do sistema de saúde.

Vale destacar, ainda nesse aspecto, em que pese a realização de vários ciclos do programa em cada um dos estados analisados, que questões gerenciais dificultam a criação do entendimento compartilhado, sobretudo a rotatividade dos atores nessas organizações. Em especial, nota-se uma rotatividade maior entre os gestores de saúde.

\footnotetext{
Uma série de fatores atrapalham, por exemplo: a rotatividade. As pessoas da Secretaria que começaram, que fizeram o marco zero já não são as mesmas que participaram da oficina de prioridades. Então a rotatividade é grande e a identificação com o objeto e aproximação, o acompanhamento linear da pesquisa fica, na minha avaliação, muito prejudicado (Entrevistado A - SES).

Um ponto negativo é que na SES a mudança de servidores é muito grande, é praticamente anual, ou, às vezes, semestral. Então, às vezes começa um programa de uma forma com aquele gestor e no meio do programa muda (Entrevistado C - FAP).
}

Finalmente, no tocante aos resultados intermediários, destaca-se que a etapa de acompanhamento e avaliação prevista no desenho do PPSUS conta com a realização de seminários focados nos resultados parciais, os quais são realizados 12 meses após o início das pesquisas, ou seja, na metade do tempo total previsto para cada uma delas. Observa-se, a partir das falas dos entrevistados, que o seminário de avaliação parcial tem cumprido seu objetivo no sentido de ser um mecanismo para identificar resultados intermediários concretos, celebrar pequenas vitórias e, eventualmente, realizar a 
correção de rumos. Sua existência é particularmente crucial quando se consideram situações em que os objetivos finais da colaboração são de longo prazo, tal como no caso da pesquisa científica (ANSELL; GASH, 2008).

\subsection{Capacidade de gestão intraorganizacional}

Diversos elementos relacionados à capacidade de gestão intraorganizacional dos atores foram apontados pelos respondentes das entrevistas e emergiram no processo de análise, de modo que convém categorizá-los separadamente. Emerson, Nabatchi e Balogh (2012) definem em seu modelo uma categoria denominada capacidade de ação conjunta, a qual representa as condições - em termos de recursos, conhecimento, liderança e arranjos organizacionais - de transformar estratégia em performance. As questões que emergiram a partir dos dados analisados, apesar de se relacionarem a essa mesma condição de implementação, são de outra ordem, qual seja, o nível de ação individual das organizações que participam do processo colaborativo.

A primeira questão que se apresenta é, como evidenciado na análise da subcategoria entendimento compartilhado, a rotatividade de pessoas, sobretudo no âmbito das secretarias de saúde dos estados analisados. Essa rotatividade foi apontada como um obstáculo ao processo de construção de confiança e trata-se de uma situação de ordem intraorganizacional, embora impacte diretamente um elemento fundamental do processo colaborativo interorganizacional, conforme explicitado anteriormente no texto.

Outra questão levantada - igualmente de natureza interna às organizações envolvidas na implementação do programa - é constituída pelos atrasos e descompassos na transferência dos recursos entre os partícipes, o que compromete a execução das pesquisas e, consequentemente, o alcance dos resultados. A fala transcrita a seguir ilustra essa situação.

\footnotetext{
Muitas vezes, a gente faz a oficina de prioridades, abre edital, classifica as propostas e, quando vai assinar o termo de outorga, não tem o recurso. Então, isso fragiliza o programa, porque a gente tem um prazo de execução. Se não tem o recurso e não tem como você executar um projeto de pesquisa, então, eu acho que a questão financeira pesa muito (Entrevistado C - FAP).
}

Alguns problemas de natureza operacional foram relatados pelos entrevistados e correspondem também a questões de capacidade de gestão interna das entidades responsáveis por cada um desses papéis: problemas com a logística de organização dos 
eventos, incluindo os formulários de avaliação; morosidade no sistema informacional que suporta a execução do programa; assim como a cronologia de avalição dos projetos.

Os aspectos ligados à operacionalização do programa por cada agente individualmente denotam a existência de um elemento, não destacado em sua plenitude no modelo teórico utilizado, que influencia o processo colaborativo, qual seja: a capacidade de gestão das organizações participantes desse processo colaborativo. Isso ocorre porque as organizações agem individualmente no sentido da execução das tarefas, ainda que decisões sejam tomadas conjuntamente no âmbito do processo colaborativo. Em outras palavras, os atores decidem alguns pontos coletivamente na arena colaborativa do programa, mas a implementação dessas decisões - a mobilização de recursos no sentido do alcance dos objetivos pactuados - é realizada separadamente por cada organização e está sujeita às suas limitações em termos gerenciais, em termos de capacidade de ação. Esse raciocínio motiva a inserção de uma categoria no modelo teórico, conforme proposto na Figura 3.

Figura 3 - Modelo de governança colaborativa adaptado

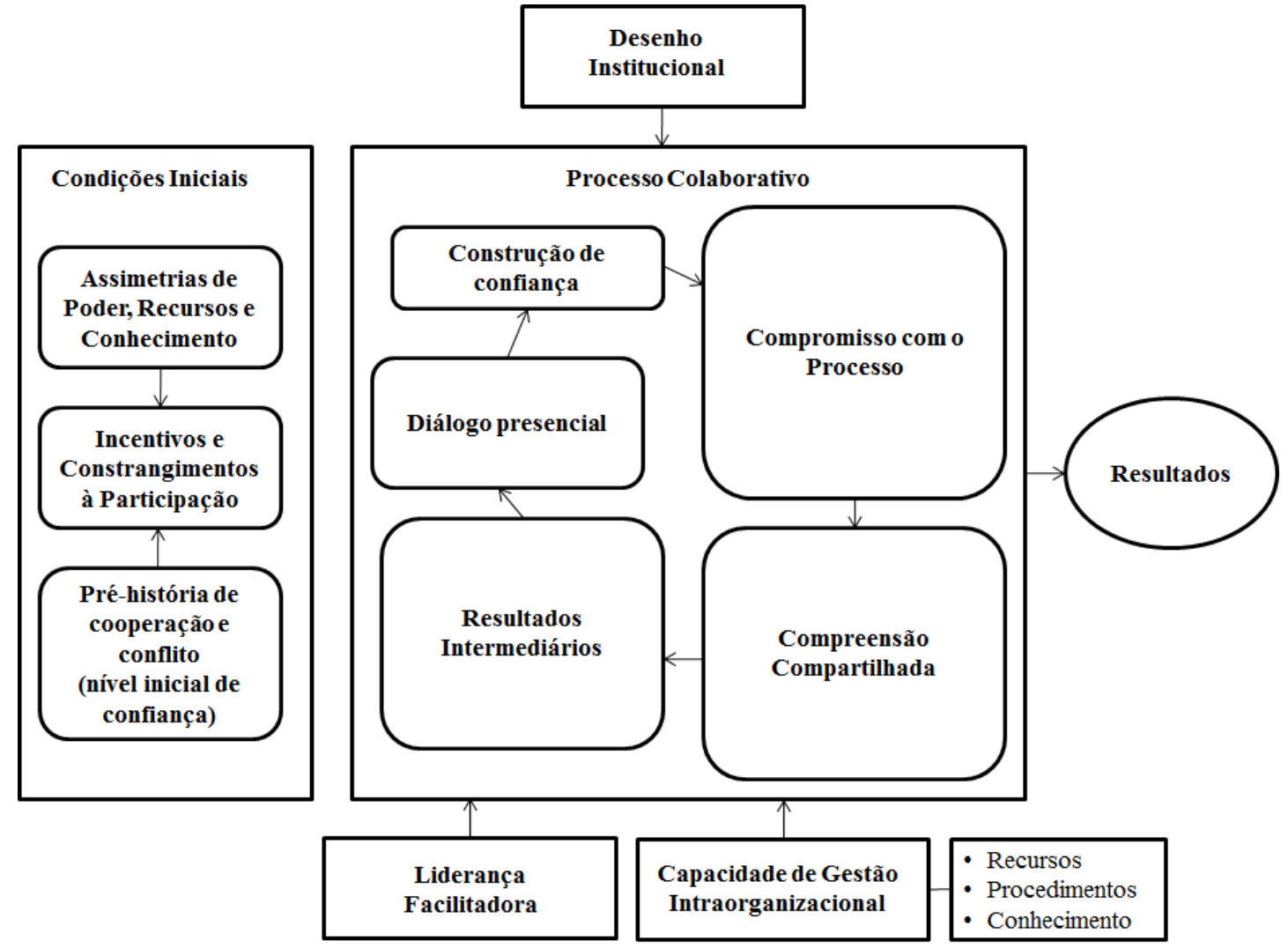

Fonte: Ansell e Gash (2008, p.550), adaptada pelos autores do trabalho, com base nos dados da pesquisa. 


\section{Conclusões}

Visando responder à primeira pergunta de pesquisa, conclui-se que o processo de governança colaborativa no âmbito do Programa Pesquisa para o SUS, nos três estados analisados, ocorre de maneira incompleta, isto é, contata-se que alguns dos elementos do modelo teórico não se verificam no caso analisado.

A formulação do PPSUS criou os incentivos para a colaboração FAP e SES, o que foi assimilado pelos gestores das FAP, os quais entendem as SES como clientes no âmbito do programa. Não obstante, esses incentivos não foram capazes de proporcionar o reconhecimento da interdependência por parte dos gestores das SES e mesmo o engajamento desses atores no processo colaborativo. Os dados apontam para uma dificuldade de mobilização dos gestores de saúde em torno dos objetivos do programa, e infere-se que essa dificuldade seja explicada pela baixa percepção de valor nos resultados das pesquisas por parte daqueles gestores, derivada de questões tais como o conflito de interesses entre pesquisadores e gestores quanto à agenda prioritária de pesquisa e a existência de obstáculo para a construção de confiança, qual seja, a rotatividade dos próprios gestores de saúde.

Exceção à descrita situação de ausência de engajamento dos gestores de saúde no PPSUS é o Estado do Paraná, o qual adota um arranjo organizacional diferenciado dos demais, imputando a responsabilidade de coordenação do programa à sua unidade de pesquisa e ensino em saúde, a Escola de Saúde Pública, locus tradicional de aproximação entre a gestão do sistema de saúde e a academia.

A partir da análise do aspecto de liderança facilitadora, conclui-se que há um vácuo de liderança na condução da arena colaborativa para todos os estados analisados, embora o arranjo organizacional específico adotado pelo Estado do Paraná supramencionado minimize esse vácuo. De qualquer maneira, mesmo nesse estado, nota-se que cada organização circunscreve suas ações a suas competências tradicionais. De maneira sintética: no caso das FAP, a mobilização da academia; e, no caso das SES, a mobilização dos gestores do sistema de saúde. Assim, cada organização envolvida no processo colaborativo não age no sentido de mediar o debate entre esses atores, restringindo-se aos limites legais de sua atuação. De acordo com a literatura, a 
existência de uma liderança facilitadora é condição sine qua non para a efetividade de um processo colaborativo.

No que se refere ao desenho institucional do PPSUS, conclui-se que as normas do programa contemplam a definição de papéis, de critérios para o alcance do consenso e de prazos, sendo esse um elemento do modelo teórico que tem correspondência no caso concreto analisado. Os atores entrevistados corroboram essa análise do desenho institucional, embora sugiram pontos de melhoria de ordens diversas.

Contata-se a existência de diálogo presencial em várias fases da execução do programa; no entanto, a construção de confiança e de entendimento compartilhado resta prejudicada pela rotatividade dos gestores do sistema de saúde. Por sua vez, o compromisso com o processo é inefetivo, na medida em que os gestores das FAP não entendem como de sua responsabilidade a incorporação dos resultados das pesquisas no sistema de saúde, isto é, não compartilham a propriedade do processo colaborativo e não reconhecem o objetivo do programa como meta conjunta. Em outras palavras, estão focados nas suas próprias competências tradicionais e na sua própria parte do trabalho. Ainda no que se refere ao compromisso com o processo colaborativo, destaca-se que os gestores de saúde não percebem valor nas pesquisas produzidas, de maneira geral. De outro lado, em relação aos resultados intermediários do processo colaborativo, nota-se que eles são identificados e celebrados nos seminários de avaliação parcial, o que faz dessa mais uma correspondência entre o modelo teórico e o caso concreto.

Elementos relacionados a aspectos burocráticos e administrativos, que emergiram a partir dos dados, levam à resposta para a segunda pergunta de pesquisa: a partir do caso analisado, propõe-se a adaptação do modelo de governança colaborativa adotado, com a criação de uma categoria de análise própria, a capacidade de gestão intraorganizacional, evidenciada pelos recursos, procedimentos e conhecimento disponíveis em cada uma das organizações participantes do processo de colaboração. Essa inserção visa adequar o modelo à realidade da administração pública brasileira, oportunizando a consideração de aspectos gerenciais em análises futuras de processos de governança colaborativa. Essa é, portanto, a principal contribuição da pesquisa ao corpo de conhecimentos produzidos na literatura a respeito da governança colaborativa.

Problemas como a rotatividade de gestores nas secretarias de saúde, atrasos e descompasso nos repasses financeiros do PPSUS e dificuldades na operacionalização 
dos eventos previstos são alguns dos pontos que indicam a necessidade de superação de entraves burocráticos do contexto gerencial da administração pública brasileira - no qual as organizações analisadas estão inseridas e do qual são tipos característicos - no sentido de permitir um efetivo processo colaborativo.

É particularmente importante ressaltar como conclusão desta pesquisa que, embora muitas das decisões no âmbito do processo colaborativo do PPSUS sejam conjuntas, a ação não o é. Em outras palavras, o que se percebe é que as decisões tomadas na seara interorganizacional do programa demandam ações intraorganizacionais de cada participante, as quais estão limitadas pela respectiva capacidade gerencial. Isso significa que nem todas as ações são de fato colaborativas e toda decisão que é tomada conjuntamente, na arena de colaboração, tem de passar pelas burocracias individuais.

Finalmente, uma agenda de pesquisa que amplie o escopo em relação a este trabalho, em termos de unidades de análise e/ou unidades de observação, abarcando outros estados e interpelando outros atores envolvidos com o PPSUS, tais como os pesquisadores, poderia elucidar novas questões a respeito do programa e seu processo colaborativo. Além disso, a categoria proposta como complementação ao modelo teórico (capacidade de gestão intraorganizacional) tem o potencial de contribuir para a compreensão de aspectos relevantes do fenômeno da governança colaborativa e pode ser utilizada em outros estudos que tenham por objeto políticas públicas desenvolvidas em contexto semelhante, a fim de se verificar a pertinência e o ajuste dessa adaptação incorporada ao modelo.

Os desafios teóricos e práticos subjacentes à governança colaborativa no setor público de maneira alguma se esgotam com este trabalho. $O$ que se pretende, modestamente, é contribuir para o entendimento dessa abordagem de condução das políticas públicas e, eventualmente, proporcionar melhorias para o modo de gestão de um programa tão relevante para a sociedade brasileira.

\section{Referências}

Agranoff, R.; McGuiRe, M. Collaborative public management: new strategies for local governments. Washington, DC: Georgetown Univ. Press., 2003.
Albuquerque, E.; Cassiolato, J. As especificidades do sistema de inovação do setor saúde. Revista de Economia Política, v. 22, n. 4, p. 134-51, 2002.

ANSELL, C.; GASH, A. Collaborative governance in theory and practice. Journal of Public 
Administration Research and Theory, v. 18, n. 4, p. 543-571, 2008.

ARRETCHE, M. Financiamento federal e gestão local de políticas sociais: o difícil equilíbrio entre regulação, responsabilidade e autonomia. Ciência \& Saúde Coletiva, v. 8, n. 2, p. 331345, 2003.

BARDIn, L. Análise de conteúdo. São Paulo: Edições 70, 1979.

BRASIL. Ministério da Saúde. Secretaria de Ciência, Tecnologia e Insumos Estratégicos. Departamento de Ciência e Tecnologia. Informes Técnicos. Descentralização no contexto do fomento à pesquisa em saúde. Revista Saúde Pública, v. 45, n. 3, p. 626-630, 2011.

BRASIL. Ministério da Saúde. Secretaria de Ciência, Tecnologia e Insumos Estratégicos. Departamento de Ciência e Tecnologia. Programa Pesquisa para o SUS: gestão compartilhada em saúde - Diretrizes Técnicas. 5. Ed. Brasília: Ministério da Saúde, 2014.

CReswell, J. W. Projeto de pesquisa: métodos qualitativo, quantitativo e misto. 2. ed. Porto Alegre: Artmed, 2007.

EMERSON, K.; NABATChI, T.; BAlOGH, S. An integrative framework for collaborative governance. Journal of Public Administration Research and Theory, v. 22, n. 1, p. 1-29, 2012.

Guimarães, R. Bases para uma política nacional de ciência, tecnologia e inovação em saúde. Ciência e Saúde Coletiva, v. 9, n. 2, p. 375-388, abr.-jun. 2004.

Guimarães, R. Pesquisa em saúde no Brasil: contexto e desafios. Revista de Saúde Pública, São Paulo, v. 40, n. esp., p. 3-10, 2006.

KETLL, D. F. Managing boundaries in american administration: the collaborative imperative. Public Administration Review, v. 66, p. 10-19, 2006.

LaVille, C.; Dionne, J. A construção do saber: manual de metodologia da pesquisa em ciências humanas. Porto Alegre: Artmed; Belo Horizonte: Editora UFMG, 1999.

MCGUIRE, M. Collaborative public managment: assessing what we know and how we know it. Public Administration Review, v. 66, p. 33-43, 2006.

MARTINS, H. F.; MARINI, C. Governança pública contemporânea: uma tentativa de dissecação conceitual. Revista do TCU, n. 130, p. 42-53, 2014.

O'LeARY, R; VIJ, N. Collaborative public management: where have we been and where are we going? The American Review of Public Administration, v. 20, n. 10, p. 1-16, 2012.

OSTROM, E. Governing the commons: the evolution of institutions for collective action. Cambridge: Cambridge Univ. Press, 1990.

PeCI, A.; PIERAnti, O.; Rodrigues, S. Governança e new public management: convergências e contradições no contexto brasileiro. Organizações e Sociedade, v. 15, p. 39-55, 2014.

Peters, B. G.; Pierre, J. Governance without government? Rethinking public administration. Journal of Public Administration Research and Theory, v. 8, n. Rhodes 1997, p. 223-243, 1998.

Pressman, J. L.; Wildavsky, A. B. Implementation: how great expectations in Washington are dashed in Oakland. California: University of California Press, 1973.

SCHWARTZMAN, S. A pesquisa científica e o interesse público. Revista Brasileira de Inovação, v. 1, n. 2, p. 361-395, jul./dez. 2002.

STOKER, G. Governance as theory: five propositions. International Social Science Journal, v. 50, n. 1, p.17-28, 1998.

TANG, S. Y.; MAZMANIAN, D. A. Understanding collaborative governance from the structural choice: politics, IAD, and transaction cost perspectives. 2010. Disponível em: <http://www.ssrn.com/abstract=1516851>. Acesso em: 24 jan. 2017. 


\section{Rafael Marques Pessoa}

https://orcid.org/0000-0001-5783-8822

Doutorando e Mestre (2017) em Administração pela Universidade Federal de Minas Gerais (UFMG). Possui graduação (2010) em Administração Pública pela Escola de Governo da Fundação João Pinheiro. Tem interesse nos temas governança colaborativa no setor público e gestão de políticas públicas, com ênfase na área de ciência, tecnologia e inovação.

E-mail: rafamape@gmail.com

\section{Reynaldo Maia Muniz}

iD https://orcid.org/0000-0002-7644-8384

Professor titular aposentado da Universidade Federal de Minas Gerais (UFMG). Doutor em Ciência Política e Administração Pública pela Universidad Complutense de Madrid (1998). Atua principalmente nos seguintes temas: estratégia e estrutura organizacional, teoria das organizações, governança corporativa, teoria da firma, poder nas organizações, políticas públicas.

E-mail: rmaiamuniz@gmail.com

\section{Ivan Beck Ckagnazaroff}

\section{iD https://orcid.org/0000-0002-8179-269X}

Professor titular da Universidade Federal de Minas Gerais (UFMG), no Centro de PósGraduação e Pesquisa em Administração. Membro do GEGOP - Grupo Espaços Deliberativos e Governança Pública. Áreas de interesse: governança pública, modernização administrativa, reforma da Administração Pública, gestão de políticas públicas.

E-mail: ivanbeck00@gmail.com 